\title{
LA ESCRITURA MEDIEVAL DE LA CORONA DE ARAGÓN (1137-1474)
}

La primera semana de junio de 1985 tenía lugar en Castelló-Benassal la tercera edición de los Cursos de Estudios Universitarios organizados por el Prof. José Trenchs Odena y dirigido, en aquella ocasión, por el Prof. Armando Petrucci, a la sazón director del Istituto di Paleografia de la Universidad de Roma. Para aquella convocatoria José Trenchs y yo teníamos que presentar el Status quaestionis de los conocimientos sobre las investigaciones en Paleografía para el ámbito territorial y cultural que constituyó la Corona de Aragón medieval. Además del estado de la cuestión se estimó oportuno realizar una investigación sobre los manuscritos reproducidos, tanto en los manuales de Paleografía españoles como en las colecciones de facsímiles. El resultado fue el que expusimos en 1985, que con el paso del tiempo ha resultado excesivamente simple, y que los años han ido madurando.

El retraso inmerecido que han debido soportar los trabajos presentados en aquel momento, ha permitido que se pueda presentar ahora esta síntesis, más serena y mejor articulada que la precedente. Es cierto -en nuestro caso- que había sido siempre yo quien se había negado a publicar aquel texto porque lo consideraba -y lo sigo considerando en la actualidad- caduco. Era necesario para alcanzar el que ahora se presenta, pero resultaba obsoleto por no reflejar el estado actual de las investigaciones en la historia de la escritura de la Corona de Aragón. Por esa circunstancia había decidido, y así se lo hice saber a José Trenchs, no publicarlo cuando en junio de 1990 me pidió los materiales para editar el Benassal III. Ahora, sin embargo, varios meses después de haber fallecido, me siento en la obligación moral de reescribir la bistoria de la escritura medieval de la confederación catalano-aragonesa incluyendo las últimas aportaciones e innovaciones fruto de las investigaciones más recientes.

No habiendo descuidado la investigación en la historia social de la escritura resulta que la puesta por escrito de los estudios particulares realizados estos 
últimos años ha hecho que alcanzase realidad un viejo proyecto de construir una historia de la escritura para el periodo cronológico y el área cultural considerada. Los resultados, excesivamente extensos, aconsejan una publicación independiente. En este sentido debe entenderse el texto que aquí se presenta como un resumen de ese amplio estudio al que me refería y que, en breve, se publicará con el título: Escribir la sociedad. El universo gráfico de la Corona de Aragón bajomedieval (1137-1474). Este texto es deudor también de una investigación que desde hace años estoy efectuando sobre los manuscritos de la literatura catalana medieval y de la que, en breve, se publicará una primicia con el título: De les Homílies a les Trobes. Models de llibres i d'escriptures de la tradició textual catalana. Este dominio se hubiera enriquecido enormemente gracias a las informaciones obtenidas por los estudios que José Trenchs desarrolló durante sus tres últimos años de vida. Una investigación centrada, especialmente, en el análisis de los libros que se copiaron para la Casa Real durante el reinado de Pedro IV el Ceremonioso. Material inédito que debe publicarse cuanto antes porque Trenchs ha sido la única persona que ha revisado al completo los registros de Cancillería de este periodo.

No cabe duda, por consiguiente, que el texto que aquí se presenta es incompleto por cuanto quedan reducidas al mínimo las notas correspondientes al aparato crítico. Cualquier lector interesado podrá encontrar noticia de todas ellas en las notas que acompañan a los estudios antes mencionados.

Finalmente, aunque José Trenchs no ha podido revisar y completar, con su enorme erudición, este estudio, he procurado en él recoger, siempre que me ha sido posible, los resultados de las investigaciones que ambos hemos desarrollado por separado.

La escritura medieval de la Corona de Aragón ha sido estudiada siempre, al menos en el presente siglo, por todos los manuales de Paleografía española. En ellos se han incluido unos pequeños apartados que analizan las distintas modalidades gráficas utilizadas en cada uno de los periodos considerados. Contaban con una tradición (aunque alejada en el tiempo) que representaba el libro de Joaquín TOS titulado Paleografía que para inteligencia de los manuscritos de este Principado, escribió..., cuya segunda edición se publicó en 1855 y con la que su autor pretendía suplir el desconocimiento general de la Paleografía con respecto a los manuscritos de la Corona de Aragón (... mayormente cuando la dirijo al conocimiento de aquellos con que se ballan escritos varios documentos de este Principado, cuya explicación se omitió tal vez hasta abora..., p. 4). Algunas de las reproducciones de manuscritos catalanes que $\mathrm{J}$. Tos reprodujo en su primera 
edición fueron copiados por Esteban PALUZIe CaNTAlOzella en la Paleografía española, que publicó en 1846 [El título amplísimo de este manual dice así: Paleografía española, por ... benemérito de la patria, bachiller en Filosofía y profesor de educación en primera clase. "Comprende una sucinta historia de la escritura adornada con los caracteres antigüos que cada nación ha tenido; un resumen del «ensayo sobre los alfabetos de las letras desconocidas que se encuentran en las más antigüas medallas y monumentos de España» que publicó D. Luis José Velázquez, un estracto del «Alfabeto de la lengua primitiva de España» de D. Juan Bautista Erro y Aspiroz; un diccionario de las abreviaturas romanas que se hallan en las lápidas, varias inscripciones romanas, godas, árabes, hebreas y cristianas; la «Bibliotheca Universal» de D. Christóbal Rodríguez, lo más selecto de la «Paleografía Española» del P. Esteban de Terreros y Pando; lo más esencial de la «escuela paleográfica, o de leer letras antigüas» por el P. Andrés Merino y la Paleografía catalana.» Barcelona, Autografía del autor, septiembre de 1846. Sobre la identificación de la Paleografía catalana con la de J. Tos, véase F.M. GIMENO BLAY, Las llamadas ciencias auxiliares de la bistoria: ¿Errónea interpretación? (Consideraciones sobre el método de investigación en Paleografía). Zaragoza, Institución Fernando el Católico, 1985, p. 102] incluyendo unos cuantos ejemplos de manuscritos catalanes. Sin embargo ambos creían que existía una unidad gráfica que afectaba a todos los estados peninsulares y como consecuencia llevó a Paluzie a poner los manuscritos catalanes en dependencia de los castellanos medievales.

Tal vez condicionados por estos precedentes o por el hecho de que las escrituras bajomedievales castellanas (la cortesana y la procesal) presentaban mayores dificultades en su lectura, los tratadistas del presente siglo descuidaban las escrituras de la Corona. Cabe, no obstante, pensar que el descuido fue intencionado y que respondía a una determinada concepción historiográfica que, partiendo del centralismo, relega a los márgenes, o incluso niega su existencia, a todo aquello discordante con la vida cultural del centro. Esta situación de omisión puede observarse analizando los manuales de Z. GARCÍA VILLADA [Paleografía española. Precedida de una introducción sobre la escritura latina. 2 vols. Madrid, 1923], de A.C. FLORIANO CUMBREÑO [Curso general de Paleografía y Paleografía y Diplomática españolas. Oviedo, 1946], y de C. MORTERERO Y SIMÓN [Apuntes de iniciación a la Paleografía española de los siglos XVI al XVII. Madrid, 1963]. Lo mismo sucedía con las dos primeras ediciones de la Paleografía de A. MILlares CARLO [Paleografía española. Ensayo de una bistoria de la escritura en España desde el siglo VIII al XVII. 2 vols. Barcelona, 1929, y Tratado de paleografía española. 2." ed., 2 vols. Madrid, 1932]; situación que sólo en parte ha sido corregida en la tercera edición, en la que se sigue manteniendo una mayor representación de las escrituras castellanas [Tratado de Paleografía española, con la colaboración de J.M. Ruiz Asencio. 3." ed., 3 vols. Madrid, 1983]. 
Del mismo modo sucedía con las colecciones de facsímiles. El oriente peninsular siempre quedaba escasamente representado. La exposición equilibrada de manuscritos procedentes de las diversas áreas culturales medievales peninsulares sólo se conseguiría en 1974 con la publicación por A. CANELLAS de sus Exempla scripturarum latinarum. Pars altera [Caesaraugustae, M.DCCCC.LXXIIII]. La recuperación definitiva se alcanzaría con la publicación de la Colectanea paleográfica de la Corona de Aragón por parte de las profesoras J. y M.D. MATEU IBARS [Barcelona, 1980, obra de la que solamente se ha publicado el vol. de facsímiles]. La aparición de esta gran colección ponía a disposición de los paleógrafos un amplio repertorio de reproducciones de manuscritos que permitían construir la historia del devenir de las. formas gráficas empleadas en la confederación catalano-aragonesa en su periodo de existencia medieval. Recogen además las distintas tradiciones escriturarias seguidas por los dos estados fundadores en el período anterior al año 1137. El interés de esta colección aumenta, especialmente, por la nueva periodización que las autoras presentan de los estilos y ciclos escriturarios que incluyen, respondiendo en la mayoría de los casos a su relación con los fenómenos artístico-culturales coetáneos. Así nos encontramos con los siguientes periodos: prerománico-románico: ciclos visigótico-carolino (s. IX-XII); cisterciense: ciclo monacal (s. XII); gótico: ciclo gótico mediterráneo (s. XIII); gótico-prehumanístico: ciclo trecentista (s. XIV); humanístico: ciclo mixtilíneo, escrituras bastardas, bumanisticas, itálicas y cánones librarios (s. XV), [Colectanea, p. 5]. No cabe duda de que en los estudios paleográficos esta clasificación de las escrituras constituye una innovación muy significativa que no puede pasarse por alto. Ahora bien falta todavía dotarla de contenido, resulta necesario caracterizar las escrituras que se han incluido en los diversos grupos. Clarificación de contenidos que se supone se expondrá, detenidamente, con la publicación del primer volumen, todavía inédito.

Transcendido el nivel de los manuales, en el que se observa -como acabamos de estudiar- una limitada atención a la historia de la escritura de la Corona de Aragón, nos econtramos con el hecho de que las investigaciones especializadas, monográficas, sobre diversos usos de la escritura durante la baja edad media son más bien escasos; fenómeno que, necesariamente, ha influido en la posterior elaboración del manual, amén de otros condicionantes ideológico-culturales que influyen directamente en la confección de este tipo de obras.

Las síntesis relativas a la evolución de la escritura en la Corona de Aragón con las que contamos en la actualidad son escasas y reducidas por cuanto forman parte de obras de referencia, como por ejemplo la publicada por A.M. MUNDÓ en la voz Paleografia de la Gran Enciclopèdia Catalana [2." ed., vol. 17, pais-Picor. Barcelona, 1988, pp. 146-148]; o están elaboradas sobre otros materiales, no los tradicionales de la Paleografía, como la que publiqué en $D e$ 
scripturis in picturis, basándome en las filacterias de la pintura [«Fragmentos. Revista de Historia del Arte», n.. 17, 18, 19, Madrid, marzo, 1991, pp. 176-183]. Diacronía gráfica, esta última, representada por las escrituras expuestas al público que presenta las mismas características formales que la colección epigráfica medieval de Valencia [F.M. GIMENO BLAY, Materiales para el estudio de las escrituras de aparato bajomedievales. La colección epigráfica de Valencia, en Walter KOCH (ed.), Epigraphik 1988. Fachtagung für mittelalterliche und neuzeitliche Epigraphik, Graz, 10-14 Mai 1988. Referate und Round-Table-Gespräche. Wien, Österreichische Akademie der Wissenschaften, 1990, pp. 195-215 más facsímiles].

Entre los estudios monográficos conviene destacar para el momento inicial, segunda mitad del siglo XII, dos importantísimos estudios de A.M. MUNDÓ, El pacte de Cazola i el Liber Feudorum Maior. Notes paleogràfiques $i$ diplomàtiques [ «Jaime I y su época. 1 y 2. X Congreso de Historia de la Corona de Aragón». Zaragoza, 1980, pp. 119-129] y Fragment del Libre Iutge, versió catalana antiga del 'Liber Iudiciorum', [«Estudis Universitaris Catalans», XXVI, IV de la tercera època, 1984, pp. 155-193] a través de los que se puede reconstruir toda la producción manuscrita de carácter librario. Además conviene recordar para todo el periodo medieval, basado en materiales aragoneses principalmente, el trabajo clásico de M. USÓN SESÉ [Contribución al estudio de la cultura medieval aragonesa. La escritura en Aragón del siglo XI al XVI. Lección inaugural del curso 1940-1941. Zaragoza, 1940] y el de F.M. GIMENO BLAY, donde se estudia la escritura gótica del País Valenciano introducida en el reino medieval después de la conquista del siglo XIII [La escritura gótica en el País Valenciano después de la conquista del siglo XIII. Valencia, 1985].

Para la Sardegna aragonese ofrecía F.C. CASULA un panorama de las formas gráficas utilizadas en el periodo anterior y posterior a la dominación de la Corona [Breve storia della scrittura in Sardegna. La documentaria nell'epoca aragonese. Cagliari, s.a.]. El mismo estudioso también se ocupaba de la escritura de este periodo bajomedieval en dos trabajos: uno dedicado al análisis morfológico de la escritura del siglo XIV [Alcune note sulla "letra aragonesa nel secolo XIV, «Annali della Facoltà di Lettere, Filosofia e Magistero della 'Università di Cagliari'», XXX (1967)], y otro a describir algunas características de la cancillería de Jaime I donde proponía por vez primera la utilización del calificativo de catalana para designar la escritura gótica empleada durante los siglos XIII y XIV, oponiéndose así al de aragonesa, adjetivo que encuentra su origen en el mencionado trabajo de M. Usón Sese [F.C. CASULA, Observaciones paleográficas y diplomáticas sobre la cancillería de Jaime I el Conquistador. "Jaime I y su época. 3, 4 y 5 . X Congreso de Historia de la Corona de Aragón». Zaragoza, 1980, pp. 433-451].

Al siglo XIV se le han dedicado muy pocos estudios. Destacan, no obstante, el de A.M. ARAGÓ incluido en su trabajo sobre La escribanía de Juan I /VIII 
Congreso de Historia de la Corona de Aragón, II. La Corona de Aragón en el siglo XIV», vol. 2. ${ }^{\circ}$, Valencia, 1970, pp. 269-293], y el de L. d'ARIENZO centrado en el tránsito de la Gótica a la Humanística, basado, fundamentalmente, en la documentación del Archivo Histórico de Protocolos de Barcelona y en la del Archivo de la Corona de Aragón [Alcune considerazioni sul passaggio della gotica all'umanistica nella produzione documentaria catalana dei secoli XIV e XV, "Studi di Paleografia e Diplomatica», Padova, 1974, pp. 199-226].

Para el siglo XV y de todo lo relativo a la aparición de la Humanística se dispone, en la actualidad, de dos trabajos que analizan, respectivamente, la presencia de este nuevo tipo en la Cancillería real [A.M. ARAGÓ, Prenotaciones a la escritura cancilleresca de Alfonso el Magnánimo». «La Corona d'Aragona e il Mediterraneo: aspetti e problemi comuni de Alfonso il Magnanimo a Ferdinando il Cattolico (1416-1516). IX Congresso di Storia della Corona d'Aragona», II, Napoli, 1982, pp. 49-55], y la introducción de la escritura humanística en Valencia [M.L. MANDINGORRA LLAVATA, La escritura bumanistica en Valencia. Su introducción y difusión en el siglo XV. Valencia, 1986]. Ahora bien, aunque este último utiliza tan sólo manuscritos valencianos, ello no es óbice para que con rigor historiográfico, y como marco general que sirve para situar el tema, afronte la autora la problemática global de la aparición de la Humanística en la Corona de Aragón a partir de las distintas contribuciones que le precedieron.

El panorama de los materiales descrito hasta este momento se completaría, ineludiblemente, con toda una serie de trabajos que, no teniendo como objetivo central la escritura, presentan comentarios, las más de las veces descriptivos, sobre las escrituras que transmiten las fuentes utilizadas.

Si refiriéndose a las escrituras procedentes de ambientes documentales denunciábamos la escasez de estudios, para las de carácter librario podríamos afirmar que las desconocemos casi completamente. Existen estudios puntuales sobre manuscritos, pero no se dispone todavía de un estudio riguroso ni para la producción textual latina ni para la vulgar. Por ello resulta sumamente actual, para el dominio de las escrituras librarias, el magnífico trabajo de P. BOHIGAS dedicado a La ilustración y la decoración del libro manuscrito en Cataluña. Contribución al estudio de la miniatura catalana [3 vols. Barcelona, 19601967].

El escaso interés que la investigación paleográfica hispana ha mostrado por las escrituras librarias, o por cualquier otro contexto de uso de la escritura (epigráfica, filacterias, monetales, etc.) está motivado por el hecho de que este sector de los estudios ha permanecido ligado siempre a la investigación histórica, de cuño positivista, que de forma obsesionada creía encontrar en la autenticidad documental la verdad histórica. La necesidad de verificar la autenticidad o falsedad del instrumento notarial o del diploma medieval hizo que cobrase un auge desmedido la vertiente diplomática de la Paleografía. 
Desmedido porque un análisis historiográfico entre el siglo XVIII y la actualidad, pone de relieve las herencias y las limitaciones que este modo de entender la investigación imponen a este conocimiento histórico, y, en definitiva, cuestionan el desarrollo de prácticas cognoscitivas alternativas. Consecuentemente, resulta necesario atender las contribuciones del pasado siempre que ayuden a delinear el futuro. La práctica de investigación desarrollada hasta este momento ha ido alejando discursos comunes sobre el uso que las sociedades pretéritas han hecho de la escritura; por ello la complacencia por el camino recorrido puede ser peligrosa. Pretender justificar la autonomía científica al margen de la Historia constituye un absurdo, y al mismo tiempo la evolución descrita por la Historia en el presente siglo ha contribuido a poner de relieve de qué modo las herencias del pasado (en Paleografía) han retrasado el conocimiento y han impedido comprender, globalmente, el uso de la escritura en una sociedad.

La Corona de Aragón medieval, por sus características políticas y culturales permite, como laboratorio intelectual de reflexión, intentar construir una historia de la escritura que aglutine todos sus usos en el periodo considerado.

\section{III}

La Corona de Aragón se constituyó como formación política por medio de la unión dinástica del reino de Aragón y los condados catalanes en 1137, culminando con la incorporación posterior de los reinos de Mallorca, Valencia, Sicilia, Sardegna, Nápoles y los ducados griegos de Atenas y Neopatria fruto de la expansión mediterránea experimentada durante los siglos XII al XV. Joan Reglà advertía que la unió entre els diversos regnes integrants és de tipus personal, dinàstic, puix que cadascun d'ells conservà la seua personalitat pròpia [J. REGLÀ, Introducció a la bistòria de la Corona d'Aragó. 2." ed. Palma de Mallorca, 1973, p. 11]. La personalidad a la que aludía Reglà hacía referencia a la diversitat de llengïes, estructures socials $i$ econòmiques que, en cierto modo, alejaban la unión de ambos estados. Sería incorrecto pensar que estas diferencias no afectaron a la estructura y funcionamiento de las escribanías en el periodo anterior a la fusión. En la actualidad sabemos que ambos estados poseyeron tradiciones gráficas, al menos formalmente, diferentes desde el lejano siglo IX en el que en los condados catalanes -por influencia franca- comenzó a sentirse la presencia de la nueva carolina, escritura que en el siglo $\mathrm{X}$ era de uso generalizado, habiendo desplazado completamente a la visigótica [vid. el estudio de A.M. MUNDÓ - J. ALTURO, La escritura de transición de la visigótica a la carolina en Cataluña del siglo IX. "Actas del VIII Coloquio del Comité Internacional de Paleografía Latina». Madrid, 1990, pp. 131-138]; escritura que, por el contrario, Aragón mantuvo en uso hasta la segunda mitad del siglo XII. 
Al definir el marco político y cultural al que limitaré nuestro discurso ha quedado definido también el punto de arranque del presente resumen, el límite a quo, es decir el año 1137 , aunque será necesario remontarse a siglos anteriores para entender el panorama gráfico de los primeros años de existencia de la Corona. El final de nuestro recorrido se alcanzará cuando lleguemos al momento de la aparición del libro impreso, año 1474 . Fue Valencia la primera ciudad de la Corona de Aragón en la que se imprimió un libro: les Trobes. La elección consciente de esta fecha radica en el hecho de todos conocido, de que la imprenta generó nuevos mecanismos de difusión de la cultura escrita y nuevos comportamientos de uso de la misma que obligan a reconocer en ese momento la existencia de una cesura.

Todo el periodo cronológico que nos proponemos analizar, es decir, desde 1137 hasta 1474, representa un espacio de tiempo muy amplio que, a fin de exponerlo de forma más coherente, parcelaremos en varios apartados.

Al referirnos a la creación de la Corona de Aragón en 1137, decíamos que la fusión de los dos estados fundadores hizo que se encontraran dos tradiciones paleográfico-diplomáticas diferentes. La nota más sobresaliente la constituye el hecho de que el reino de Aragón en su periodo de vida independiente (es decir entre 1035 y 1137) utilizó en ambiente documental la escritura visigótica, tradición escrituraria que se mantuvo en uso hasta la época del reinado de Alfonso II. A la escritura acompañaron -en la escribania- unos usos diplomáticos que se caracterizaron (además del tenor) por el empleo de una mise en page de los documentos muy concreta. El soporte, pergamino con forma apaisada, quedaba distribuido del siguiente modo: (a) el crismon y el texto; (b) un espacio, en blanco, central con la suscripción real, es decir del autor jurídico; (c) el espacio destinado al escatocolo, integrando la datación y la lista de seniores et tenentes y, finalmente, (d) la claudatio del rogatario.

A diferencia del reino aragonés los condados catalanes escribían ya en carolina desde el siglo X [F. UDINA MARTORELL, El archivo condal de Barcelona. Barcelona, 1951]. Sin embargo, ya a principios del siglo IX la visigótica local dejaba sentir la presencia de elementos carolinos. Véase a modo de ejemplo el acta de consagración de la iglesia del castillo de la Pobla de Lillet, datada en el año 833 [Urgell. Archivo de la Catedral]. En el siglo XII, es decir en el momento de fusión de ambos estados, las carolinas catalanas ya se habían transformado en góticas primitivas o protogóticas, según la terminología de A.M. Mundó.

He aquí, por consiguiente, que al constituirse la Corona de Aragón nos 
encontramos con una situación gráfica que designaremos, siguiendo la terminología de A. Petrucci, de multigrafismo relativo. Se trata de un ambiente en el que conviven, sin que entre ellos exista una relación jerárquica, dos tipos de escritura: la visigótica y la gótica. Pero, no hay que olvidar que esta diferencia gráfica constituye el síntoma externo de una división que afectaba a las esctructuras sociales, que las prácticas de escritura relacionadas con la producción documental reflejan bien. Tanto la mise en page como las fórmulas del tenor formulario relativas a la intervención de los rogatarios eran diferentes [Véase sobre este asunto el trabajo de A.M. ARAGÓ - J. TRENCHS, Las escribanias reales catalano-aragonesas de Ramón Berenguer IV a la minoría de Jaime I. «Revista de Archivos, Bibliotecas y Museos», LXXX (1977) pp. 421-442]. La escribanía actuante después de la fusión mantuvo en vigencia todas estas peculiaridades, de tal modo que sólo con observar el aspecto externo de los documentos se puede reconocer a qué dominio cultural pertenece el destinatario de la documentación y quién es el posible receptor de la acción jurídica.

Pero esta situación fue superándose conforme se caminaba hacia el final del siglo y se consolidaba el proceso de fusión. Este proceso conllevó una mayor organización de la oficina de expedición documental y en él la escritura desempeñó un papel significativo. Consecuencia lógica de la necesidad de alcanzar una individualización gráfica en la producción documental de la segunda mitad del siglo XII fue el hecho de que la visigótica aragonesa y la forma especial de presentación del texto dejaron de utilizarse en beneficio de una unificación gráfica basada en la gótica. El último testimonio de uso de la visigótica en documentación aragonesa data del año 1162. Sin embargo, la difusión previa de las plumas biseladas góticas, en una situación de cohabitación gráfica, tuvo como consecuencia la presencia de contrastes de trazos, característicamente góticos en algunas escrituras visigóticas tardías.

A partir de este momento ya sólo se escribirá en gótica, aunque las formas gráficas empleadas en esta segunda mitad del siglo no presentarán una uniformidad sino que mostrarán dos manifestaciones diferenciadas: una libraria y otra cursiva ¿A qué se debe esta indistinción gráfica? Siendo la cursiva minoritaria, se explicaría la presencia de la libraria en ámbito documental por el hecho de que muchas veces quienes actúan como rogatarios de la documentación privada y pública son eclesiásticos o personas formadas en ambientes librarios. Esta duplicidad de filones gráficos se mantendrá en uso hasta finales del siglo XII, momento en el que triunfará el cursivo, convirtiéndose en la tendencia dominante y hegemónica, y sobre la que se iniciará el proceso de canonización gráfica. Efectivamente, durante el reinado de Alfonso II comienzan a percibirse algunas de las características que serán definitorias en el proceso de individualización de la Cancillería del siglo XIII. La aparición de algunas como el cuerpo pequeño de las letras en relación con los alzados y los caídos, o los residuos de la 
minúscula diplomática francesa (litterae elongatae, treillis, etc.) permiten relacionar este decantamiento hacia el filón cursivo con la evolución coetánea europea. La selección de la cursiva en época de Alfonso II y la tendencia hacia una individualización de la producción escrita darán lugar a la aparición en tiempos de Pedro II, el Católico, de la escritura designada como minúscula diplomática; denominación incorrecta, cuya modificación no resulta sin embargo necesaria puesto que detrás de este nombre existe un tipo escriturario bien definido que preludia las formas de la gótica documental del siglo XIII. La minúscula diplomática de época de Pedro II constituye la escritura sobre la que se efectuará la búsqueda del tipo que individualice a la Cancillería, es decir la gótica catalana.

Mientras tanto, ¿qué sucedía en esta segunda mitad del siglo XII en ámbito librario? La escasez de estudios relativos a este dominio de uso de las escrituras no permite reconstruir con la precisión necesaria la evolución de las góticas librarias desde las primitivas hasta las textuales del siglo XIII.Pero, en la última década del s. XII las góticas textuales están ya plenamente formadas como muestra el Liber Feudorum Maior [Barcelona. Archivo de la Corona de Aragón], que según Mundó, fou acabat i presentat al rei el 1192. Formación que se puede estudiar analizando el uso de esta modalidad en campo documental, tal y como se ha dicho anteriormente.

Tal vez lo más significativo de este periodo es que en él el catalán literario alcanzó el derecho de escritura y a este periodo pertenecen tanto las Homilies d'Organyà [Barcelona. Biblioteca de Cataluña, ms. 289] como la versión catalana del Libre Iutge [Montserrat. Biblioteca del monasterio, núm. 1109], cuya escritura es más tardía que la de las Homilies. Pero, aunque los dos presentan góticas textuales, sin embargo estas no responden a una misma calidad ejecutiva. Mientras que es plausible que el fragmento del Libre Iutge fuera copiado en un ambiente urbano próximo a la corte, tal vez en los lugares propios de la producción manuscrita del $\mathbf{s}$. XII (extremo que corrobararían tanto la gótica textual de buena calidad empleada como la presentación del texto), sin embargo el ambiente de escrituración de las Homilies es distinto. Posiblemente fueran escritas en ambiente rural, por un copista no profesional, extremo que corroborarían la calidad y preparación del pergamino, a todas luces inferior a la del Libre Iutge.

El ambiente de la producción libraria de esta segunda mitad del s. XII no se alejó del que predominaba en el resto de paises europeos. Así a finales del s. XII se asiste a una transformación gráfica que da lugar a un tipo di alfabeto maiuscolo, largamente adoperato sia nei manoscritti, sia nelle inscrizioni lapidarie, derivato con rigonfiamenti e raddoppiamenti di tratti dell'alfabeto dell'onciale e da elementi della capitale [A. PETRUCCI, Breve storia della scrittura latina. Roma, 1989 , p. 130]. Con este alfabeto, precisamente, se pondrían en contacto la 
producción manuscrita y el uso público de las escrituras de aparato, inscripciones epigráficas y filacterias de la pintura. La trnsformación de las mayúsculas románicas y su sustitución por las góticas en ambiente librario pronto fue recogida por el sector de las escrituras expuestas.

La inexistencia de publicaciones de inscripciones epigráficas obliga a concentrar la atención sobre las escrituras de la pintura. Ciertamente, a finales del siglo XII aparecen unas escrituras mayúsculas que, aún siendo románicas, dejan entrever elementos góticos (sobre todo el redondeamiento de algunas partes de la $A$ y la desaparición de la como muestra el Frontal d'Espinelves o dels tres reis [Vic. Museu Episcopal, núm. inventario 7. Reproducido en Millenum. Història i Art de l'Església catalana. Barcelona, 1989, p. 155]. La transformación definitiva, ya en el siglo XIII, dará como resultado las góticas mayúsculas que aparecen en la pintura del fresco representando a santa Catalina, procedente de la iglesia parroquial de Isavarre [Barcelona. Museu d'Art de Catalunya, núm. 69507, reproducido en Entorn a Jaume I. De L'Art Romànic a l'Art Gòtic. Tresors del Museu d'Art de Catalunya. Valencia, 1989, p.381. Este tipo de alfabeto fue de uso generalizado para todas las escrituras de aparato, tanto inscripciones como filacterias, hasta bien entrado el s. XIV en que fueron sustituidas por las minúsculas góticas textuales. Otros ejemplos de mayúsculas los constituyen la inscripción de la Porta del Palau de la catedral de Valencia, del año 1262 ca., y las filacterias incluidas en las pinturas murales de la Seu vella de Lleida, ca. 1300. Ambas presentan siempre las mayúsculas góticas. Su sustitución por las minúsculas se conseguirá cuando el modo de producción libraria bajo medieval entre en crisis al hacer su aparición en escena el libro registro en el ámbito del libro vulgar, como se verá más adelante.

El siglo XIII, por lo que a la cultura escrita se refiere, constituye un periodo importantísimo. Destacaría dos elementos significativos de este siglo. En primer lugar, la canonización de la gótica documental, y en segundo lugar el inicio de una interesantísima situación de multigrafismo absoluto generada por la expansión territorial.

Efectivamente, es durante el reinado de Jaime I cuando se completa el proceso de canonización gráfica iniciado en la segunda mitad del siglo XII, al decantarse la escribanía por el filón cursivo y haber desechado el librario en un proceso que pretendía alcanzar la máxima individualización gráfica, frente al resto de oficinas de expedición documental bajomedieval. Esta búsqueda gráfica se vio acompañada de una creciente complejidad burocráticoadministrativa de la propia escribanía. La aparición del cargo de canciller en 
época de Jaime I sería una prueba de que se estaba asistiendo a una mayor complejidad organizativa [Cfr. J. TRENCHS-A.M. ARAGÓ, Las cancillerias de la corona de Aragón y Mallorca desde Jaime I a la muerte de Juan II. Zaragoza, 1983]. La base gráfica sobre la que se elabora la gótica documental tiene como origen la minúscula diplomática del reinado de Pedro II el Católico. De esta conserva el contraste del cuerpo pequeño de las letras en relación a los alzados y caídos que, ahora durante el s. XIII, los escribanos prolongan considerablemente ocupando los amplios espacios de las interlíneas. Poco a poco esta «moda» de escribir afectará a todos los contextos sociales, creando una especie de koiné gráfica que engloba a todas las interpretaciones gráficas producidas a lo largo de este siglo.

F.C. Casula ha señalado el año 1246 como momento cronológico en el que se había alcanzado el final del proceso de canonización [F.C. CASULA, Observaciones, cit.]. No interesa tanto decir que la canonización se ha producido en el momento concreto como advertir la importancia del fenómeno en cuanto que constituye el punto final de una búsqueda consciente tendente a la elaboración de una norma gráfica. El resultado final será un modo, una manera especial de escribir, que identificará a la Cancillería como centro de producción documental.

La cuestion de los calificativos con los que se pretende definir esta escritura merece una última reflexión. En 1940 M. Usón Sesé se refería a la escritura documental de la Corona de Aragón como aragonesa. El calificativo se fue extendiendo y ha sido utilizado por varias generaciones de paleógrafos hasta que en 1977 F.C. Casula propuso que fuera sustituido por el de catalana, afirmando que su origen gráfico aconsejaba designarla de este modo, puesto que en el momento de la fusión de ambos estados la gótica ya estaba en uso en los condados catalanes. Lo cierto es que la designación es indiferente, a pesar de que algunos notarios medievales ya se refirieron a estas documentales como catalana, puesto que no constituye más que una categoría de analisis.

La espectacular expansión territorial de la Corona de Aragón durante el siglo XIII hizo cada vez más necesaria la convivencia de dos, y a veces tres, sistemas de escritura en una situación de multigrafismo absoluto. La conquista de tierras suponía que la población sometida debía aceptar, entre otras cosas, los vehículos comunicativos impuestos por los conquistadores. Uno bien significativo lo constituyó la escritura latina, que en ese preciso momento se encontraba en el periodo gótico. Se hizo inevitable la coexistencia de la escritura latina con la árabe y, en menor medida, con la hebrea. 
Tal vez el texto que mejor describa esta situación sea la referencia a la carta puebla de la Serra d'Eslida (1242) de la que se dice: scripta erat latinas dictionibus et interlineata litteris arabicis vel sarracenicis[M.C. BARCELÓ TORRES, La llengua àrab al País Valencià (segles VIII al XVI), "Arguments», 4 (1979) pp. 123-139, nota número 56]. No cabe duda de que la propia Cancillería consciente de la necesidad que tenía de entrar en contacto con la población sometida se vio obligada a usar estas escrituras, y en este contexto ha de situarse el nombramiento que Jaime II concedió, en 1294, al judío Jafuda Bonsenyor otorgándole la facultad ad recipiendum et conficiendum instrumenta debitoria arabice facienda per sarracenos [editado por A. RUBIÓ Y LLUCH, Documents per l'bistòria de la cultura catalana mig-eval, I, Barcelona, 1908, doc. XII, pp. 11-12, el texto citado en p. 11].

Que la situación de multigrafismo absoluto afectó a todos los contextos de uso de la cultura escrita lo demostraría la utilización de alafias o textos árabes, más o menos complejos, como decoración en la cerámica [Entre las piezas cerámicas conservadas en el Museo Nacional de Cerámica «González Martí» de Valencia se encuentran suficientes ejemplos], o la descripción que el rey Pedro IV hizo en 1362 de un libro que contenía la lectura del astrolabio, y que decía así:... «lo qual libre és aytal: és rubrica de lectura de stelabre e és ab cuberta vermella empremtada e ha tancadors d'argent semblants que han comunament llibres de dret, e es escrit en pergamí a colondells, e la .i. colondell és de letra critiana en lenguatge català e l'altre colondell és letra serrahinesca.... [ed. por A. RUBIó y LLUCH, Documents, I, doc. CCIII, p. 200].

La convivencia pacífica de sistemas de escritura tan diferentes finalizará de forma violenta en 1609, cuando la monarquía hispánica decrete la expulsión definitiva de los moriscos, tras reiterados intentos de asimilación cultural.

La doctrina paleográfica siempre había afirmado que, una vez alcanzada la canonización gráfica en época de Jaime I, la escritura se mantenía de forma inalterada hasta finales del reinado de Pedro IV el Ceremonioso en el que se produjo una transformación que daría lugar a una nueva escritura, designada por algunos como bastarda. El esquema resultante es excesivamente rígido, y a veces se presenta alejado de la realidad gráfica, bien distinta. El cambio descrito, a fines del siglo XIV, no surge ex nibilo y hay que buscar sus orígenes a lo largo de todo el siglo, porque las formas gráficas alcanzadas (y que han sido designadas como bastardas) ya existen al menos desde la primera mitad del siglo XIV. Una prueba la constituiría la mano más antigua del manuscrito K.I.6 de la biblioteca de El Escorial, datable hacia 1343, o la propia escritura 
autógrafa de Pedro IV [Barcelona. Archivo Corona de Aragón. Col. autógrafos]. Todas ellas hacen necesario revisar el rígido esquema de análisis propuesto hasta este momento.

Existe, y se puede apreciar a través de las colecciones de facsímiles (como la Colectánea), una tendencia generalizada entre todas las escrituras documentales (ya en la primera mitad del siglo XIV), que hace preludiar las formas características de la minúscula cancilleresca y bastarda, escrituras dominantes en la segunda mitad del siglo. ¿Cómo se consigue? No se sabe con certeza. Ahora bien convendrá tener presente al valorar este periodo y la formación de la minúscula cancilleresca local, los siguientes factores:

a) ¿de qué modo afectó a este proceso el mayor contacto con la mininúscula cancilleresca italiana a partir de la conquista siciliana de 1283? , y

b) ¿de qué forma le afectó la convergencia gráfica aviñonesa de principios del XIV, que presentó la confluencia en uso de minúsculas cancillerescas y bastardas?

El resultado, a lo largo de todo el siglo XIV, es un complejo panorama donde coexisten formas gráficas muy parecidas a las del XIII y otras que se aproximan a las minúsculas cancillerescas [Escorial, ms. K.I.6]. Además, circunscritas a finales del siglo -reinado de Juan I- y limitadas en su uso a los ambientes curiales, estuvieron presentes las bastardas de impronta francesa. Completando este rico y variado panorama gráfico, deben tenerse en cuenta también toda la gama de escrituras profesionales que se difundían cada vez más y entre ellas conviene destacar la mercantesca

Pero, aún siendo interesante el análisis de las transformaciones formales de las escrituras documentales, el liderazgo en este momento -primera mitad del siglo XIV- reside en el dominio librario. Efectivamente, la primera mitad del siglo vio cómo el monolítico sistema de producción del manuscrito ligado a los ambientes de la cultura eclesiástico-universitaria perdía su hegemonía y se iniciaba un nuevo periodo muy fructífero para la transmisión de los textos, principalmente en vulgar. Efectivamente, desde finales del siglo XIII había hecho aparación en escena el que sería el libro registro tan característico de la tradición textual en vulgar [Sobre el contexto gráfico en el que aparece este tipo de libros, veáse el trabajo de F.M. GIMENO BLAY, A propósito del manuscrito vulgar del trescientos: El escurialense K.I.6. y la minúscula cursiva libraria de la Corona de Aragón, «Scrittura e Civiltà», 15 (1991) (en prensa)]. Se caracterizó, en un primer momento, por ser libro de tamaño cuarto, escrito en papel con escrituras procedentes de ámbitos documentales como muestran algunos ma- 
nuscritos copiados en esta época como el Canf̧oner dels comtes d'Urgell [Madrid. Biblioteca Nacional, Res. 48], el misceláneo jurídico del Escorial Z.III.14, el poema de la passió de la Biblioteca Nacional de París [esp. 472], entre otros. Al alcanzar los años centrales del siglo XIV el libro registro había conseguido ya unas características que sólo variarán parcialmente: el formato se había ampliado al folio o al in-folio y se había asistido a un proceso de textualización por el que el libro, y sobre todo la escritura, se presentaban ya como escrituras librarias. El modelo de libro registro, en los formatos descritos, pervivió hasta finales de la edad media y llegó a dar vida a uno de los tipos de libro usado para los incunables, como se puede apreciar en el caso de Tirant lo Blanch, impreso en Valencia en 1490 por Nicolau Spindeler. En él la caja de escritura, distribuida en dos columnas y rodeada por una exhuberante orla, recuerda algunos manuscritos de la literatura catalana que se presentaron como libros registro de lujo, como muestra la versión catalana de la Biblia contenida en el manuscrito espagnol 2 de la Biblioteca Nacional de París, cuya primera página bien podía haber servido de modelo para las orlas de algunos incunables.

Sin embargo no fue este el único tipo de libro utilizado en la transmisión textual de la literatura catalana. Otras obras fueron escritas utilizando los manuscritos procedentes de otros ambientes sociales y culturales y empleando las góticas textuales, el pergamino y, siempre que fuese posible, una profusa decoración con minuaturas [La lista de manuscritos sería interminable. Sólo mencionaremos dos ejemplos, uno para el XIV y otro para el XV. El primero la Cirugia en catalán, datado en 1310, conservado en la Universitätsbibliotbek de Graz, ms. latín 342. El segundo las Ordinacions de la Casa Reial promulgadas por Pedro IV; de la rica tradición manuscrita de esta obra véase el ms. esp. 8 de la la Biblioteca Nacional de París, datado en 1461]. Aparecía así un libro de lujo que dependía, en su existencia, de la persona que lo sufragase. Como el libro registro, pervivió durante el resto de la Edad Media e incluso en épocas posteriores, aunque en estas su uso quedó confinado a sectores sociales para los que el libro no constituía un útil de trabajo intelectual.

Ahora bien, la diversificación de la producción libraria en la primera mitad del siglo XIV se proyectó sobre el mundo de las escrituras expuestas y provocó como consecuencia la sustitución de las mayúsculas góticas -que se habían afirmado como hegemónicas a principios del s. XIII- por las minúsculas textuales. De este modo el espacio de las escrituras de aparato quedaba reservado a las textuales frente a las cursivas, que habían invadido el campo 
librario. De este modo tan simple la sociedad medieval había jerarquizado las diversas tradiciones textuales (y culturales) vigentes. El cambio se produjo en la segunda mitad del siglo XIV, tanto en el ámbito de las inscripciones epigráficas como en el de las filacterias de la pintura.

La Virgen con el Niño de la Rectoría de santa María la Mayor de Inca permite datar este fenómeno del tránsito desde las mayúsculas a las minúsculas. Efectivamente el año 1373, según reza una inscripción al pie de la Virgen cuyo tenor es: JOAN + :DAURER: PINTOR: MA PINTADE: L'A(N)Y: M. ${ }^{\circ}$ CCC LXXIII, el pintor Joan Daurer concluía los trabajos de este tríptico, ahora fragmentario. El texto que se ha transcrito aparece en mayúsculas, mientras que una cartela desplegada entre las dos manos del niño Jesús incluía el texto: ego sum lux $m u(n)$ [di] en minúsculas góticas textuales. A partir de este momento -y siempre teniendo en cuenta la información pictórica- se empleó la minúscula textual -como escritura de aparato-, llegando incluso hasta los primeros años del s. XVI como muestra la Virgen de la Sapiencia de la Universitat de València [Capilla de la Universitat] pintada por Nicolau Falcó en 1517. La importancia de este testimonio tardío radica en el hecho de que el contexto gráfico que representa es el de un multigrafismo relativo desorganizado en el que han hecho su aparación las capitales renacentitas de gusto clásico. Este tipo escriturario ya se venía utilizando desde la segunda mitad del siglo $\mathrm{XV}$, durante un periodo en el que la minúscula gótica textual presentaba un carácter de artificiosidad, propio de las escrituras ejecutadas fuera de su tiempo.

Pero con ser significativo el paso de las mayúsculas a las minúsculas no constituye el único aspecto del fenómeno. La desaparición de las mayúsculas comportó el uso irregular -cuando no inexistente- de los signos de interpunción verticales, haciendo más dificil y compleja la lectura del texto. Al mismo tiempo se diversifican y complican los textos incluidos en las cartelas [veáse, a modo de ejemplo, el texto que recuerda el committente en el caso de la Virgen con el Niño del Maestro de Lanaja. Madrid. Museo Lázaro Galdiano], que ya no se exponen en lugares preeminentes como había sucedido en los periodos románico y gótico hasta mediados del s. XIV. Finalmente, todo ello se vio acompañado de un incremento del vulgar como lengua escrita expuesta, que cederá paso en el $\mathbf{s}$. XV al uso del latín como compañero de las capitales humanísticas.

\section{4}

El final del trayecto descrito por la escritura medieval en la Corona de Aragón lo constituye la sustitución de la gótica por la bumanistica. El estado actual de los estudios no permite precisar con claridad la cesura que marca el 
tránsito de una a otra. Dos circunstancias contribuyen decisivamente a ello: la escasez de trabajos relativos a su presencia [M.L. MANDINGORRA, La escritura bumanistica, cit.] y uso, por una parte, y el hecho de que no exista un tiempo único de evolución gráfica, por otra. Según los dominios y contextos de uso se obtiene una cronología u otra. Ahora bien lo que si se puede afirmar en la actualidad es que la humanística local nada tuvo que ver con la antiqua italiana que fue, como es de sobra conocido, un producto de lujo limitado a una élite cultural, como demuestran por ejemplo los manuscritos procedentes de la biblioteca napolitana copiados para Alfonso el Magnánimo [cfr. A. PETRUCCI, Biblioteca, libri, scritture nella Napoli argonese, en G. CAVALLO (ed.) Le biblioteche nel mondo antico e medievale, a cura di ... Bari, 1988, pp. 187202].

La humanística, antiqua, tuvo una escasa difusión en los territorios peninsulares de la Corona de Aragón y sólo fue empleada por copistas que estuvieron en relación con la corte napolitana, entre los que cabe citar al calígrafo tarraconense Bernat Audor, del que se conoce un manuscrito con las obras de Salustio [Escorial. Biblioteca del monasterio, O.III.6]; a Gabriel Altadell, del que se conservan muchos manuscritos copiados con una perfecta humanística antiqua [Eticas de Aristóteles, de la British Library de Londres, ms. Additional 21120, o el ms. misceláneo de la Biblioteca Universitaria de Valencia núm. 839 que contiene las Regule Grammatice de Guarino de Verona y el De verborum proprietate de B. Facio; entre otros manuscritos copiados por G. Altadell y del que en breve publicaré un estudio sobre sus competencias caligráficas].

El único contexto gráfico que sí parece haber dejado sentir la presencia de las formas redondeadas humanísticas fue el de la producción documental de la Cancillería, donde la correspondencia y el contacto epistolar favorecerían la difusión de las nuevas formas.

Distinto es el caso de la producción del libro vulgar. Constituye un dominio en el que se emplea en la segunda mitad del XV (sobre todo en el libro registro) una escritura híbrida en cuya formación han intervendido elementos de la minúscula cancilleresca, la textual redonda y una ejecución redondeada de las formas [vid. a modo de ejemplo el ms. 167 de la Biblioteca Capitular de Valencia, datado en 1452-1453]. Sólo a través de este estadio mixto se explican las escrituras de algunos manuscritos de la segunda mitad del s. XV como la Biblia catalana de la Biblioteca Nacional de París [ms. esp. 2], la de la British Library [ms. Egerton 1526], o, ya en una fecha más tardía (últimas décadas del XV), la escritura del Vat. Lat. 4806, único ejemplar manuscrito del Spill de Jaume Roig

El libro vulgar utilizó, además, otros tipos de escritura. Para el libro de lujo empleó las góticas textuales según venía haciéndose en épocas anteriores 
[vid. a modo de ejemplo el ms. 1420 de la Biblioteca de la Universidad de Barcelona que contiene la versión catalana de la Regla de s. Benet]. Al mismo tiempo la transmisión de obras humanísticas o de la antigüedad clásica en versión catalana utilizó nuevas formas de escritura, humanísticas cursivas, y de libro alejados de la tradición medieval como se puede apreciar en el Corvatxo de Boccaccio de la Biblioteca Nacional de Madrid [ms. 17.675] o en las Tragedias de Séneca de la misma biblioteca [ms. 14.704]. Este modelo de libro que acabará difundiéndose al final de siglo y se utilizará también para las obras propias de la literatura de la Corona [Crónica de S. Juan de la Peña. Madrid. Biblioteca del Palacio Real, ms. 3066] o para manuscritos que, concebidos como recolecciones humanísticas, integran textos de autores diversos, humanistas, en catalán [veáse a modo de ejemplo el misceláneo 17 de la Biblioteca Universitaria de Barcelona].

La aparición en Valencia en 1474 de Les Trobes, primer libro impreso de la Corona de Aragón, hará triunfar un modelo de libro y de escritura escasamente difundidos, el humanístico. No obstante, pervivirían los modelos medievales, como muestra la edición incunable del Tirant lo Blanch. Los libros de lujo desaparecerán de los cenáculos intelectuales y quedarán confinados a ambientes para los que el libro ha dejado de ser un útil intelectual.

\section{FRANCISCO M. GIMENO BLAY Y JOSÉ TRENCHS ODENA († 9-IV-1991) Universitat de València}

\section{RÉSUMÉ}

Ce travail présente, de manière schématique, l'évolution des formes adoptées par l'écriture dans la Couronne d'Aragon de 1137 à 1474 . La période chronologique analysée comprend les variantes exactes de la gothique et de l'humanistique. Ce n'est pas seulement l'aspect extérieur et la chronologie de chacune qui y sont décrits, on a prétendu, aussi, y reconstruire les différents contextes en usage de l'écriture et les caractéristiques exactes qu'elle a adopté en tenant compte de la diversité de sa fonction. Etant donné que le terrain le plus étudié est la Chancellerie royale, sa documentation agit en tant que fil conducteur du travail. Cela n'empêche pas que l'on démontre, à travers des textes, d'autres matériaux (épigraphiques, phylactères, de livres, etc.) qui permettront de reconstituer l'histoire complète de l'écriture médiévale employée dans les différents milieux. 


\section{SUMMARY}

In this study, we analyze concisely the evolution of the forms adopted by the script of the Crown of Aragon, from 1137 until 1474. The chronological period analyzed includes the formal variations of the gothic and the humanistic ones. We have not only described the external aspect and the chronology for both of them, but we have also tried to rebuild the different contexts of use of the writing and the formal characteristics that it adopted, as far as the different functionality is concerned. Given that the most studied field is the Royal Cancillería, its documentation forms the leading thread of this article. Moreover, other material (epigraphic, phylactery, from books, etc.) will allow us to rebuild the whole history of medieval script used in the different fields. 